\section{Fracture du pénis}

\section{Fracture of the penis}

\section{Y. Auffret $\cdot$ S. Serey Eiffel $\cdot$ V. Pacalin $\cdot$ C. Petit}

Reçu le 13 novembre 2013; accepté le 10 janvier 2014

(C) SFMU et Springer-Verlag France 2014

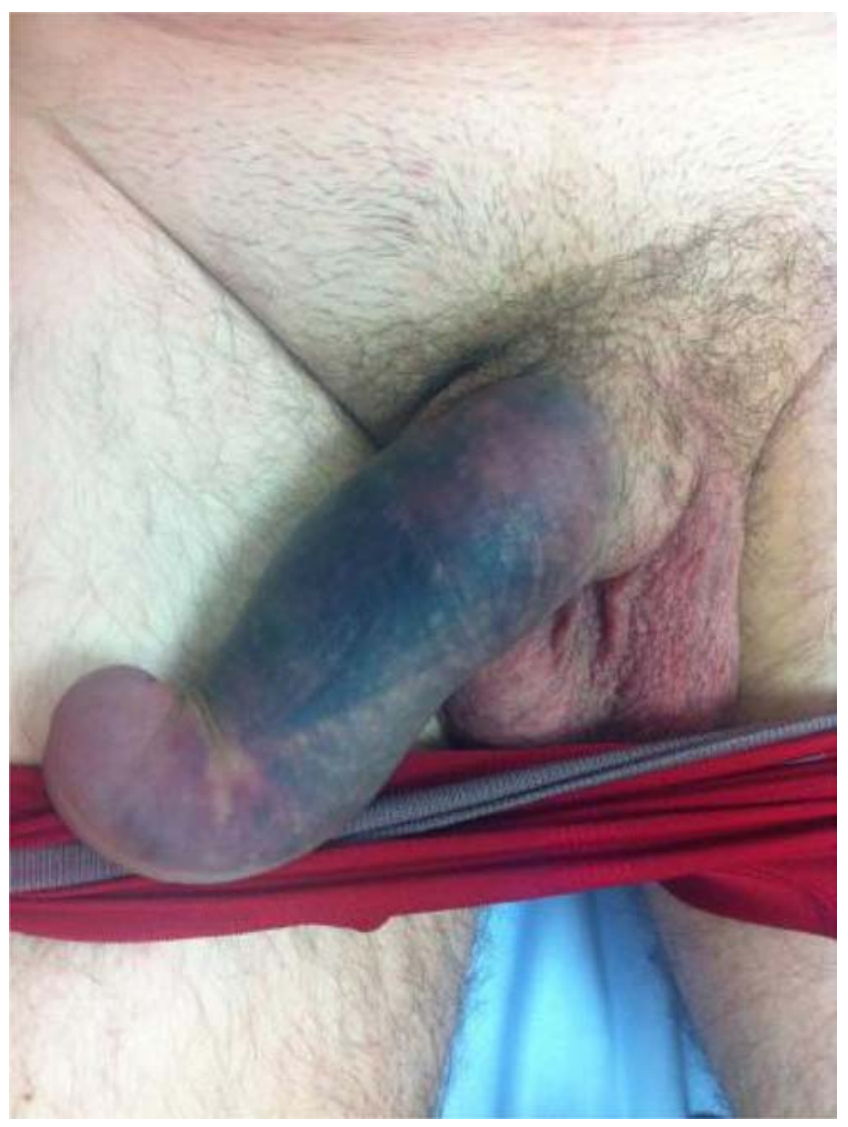

Fig. 1 Fracture de corps caverneux
Un homme de 45 ans sans antécédent se présente aux urgences suite à un traumatisme de la verge lors d'un rapport sexuel. À l'interrogatoire, on ne retrouve pas la notion de faux pas coïtal ou de conduite à risque. Le patient a ressenti une violente douleur pendant un rapport sexuel et entendu un craquement. À l'examen : on note un hématome étendu de la verge de couleur aubergine, associé à une déformation importante de l'extrémité distale de la verge (Fig. 1). Le diagnostic posé est celui de fracture de corps caverneux, confirmé par la réalisation d'une échographie. Le traitement est chirurgical, consistant en une évacuation de l'hématome et une suture de l'albuginée entourant le corps caverneux. Les suites opératoires ont été simples. Le patient a dû observer un repos sexuel pendant six semaines. Si le diagnostic de fracture de corps caverneux est extrêmement connu dans le milieu médical et ne pose pas de problème diagnostic, il est rare. Les risques à ne pas méconnaître sont la rétention d'urines (absente dans le cas présent) et la fracture associée de l'urètre (dans 10 à $30 \%$ des cas). L'urétrorragie doit alerter le clinicien et contre-indique la pose d'une sonde vésicale en urgence sans l'avis d'un urologue [1].

\section{Référence}

1. Grima F, Paparel P, Devonec M, et al (2006) Management of corpus cavernosum trauma. Prog Urol 16:12-8
Y. Auffret $(\bowtie) \cdot$ S. Serey Eiffel $\cdot$ V. Pacalin $\cdot$ C. Petit Urgences Smur, CH Quimper, 14, avenue Yves Thepot, F-29000 Quimper, France

e-mail : y.aunmail@yahoo.fr 